NBER WORKING PAPER SERIES

\title{
DO REGULATIONS BASED ON CREDIT RATINGS AFFECT A FIRM'S COST OF CAPITAL?
}

\author{
Darren J. Kisgen \\ Philip E. Strahan \\ Working Paper 14890 \\ http://www.nber.org/papers/w14890
NATIONAL BUREAU OF ECONOMIC RESEARCH
1050 Massachusetts Avenue
Cambridge, MA 02138
April 2009

We thank seminar participants at Boston College, Bentley University and Dalhousie University. The views expressed herein are those of the author(s) and do not necessarily reflect the views of the National Bureau of Economic Research.

NBER working papers are circulated for discussion and comment purposes. They have not been peerreviewed or been subject to the review by the NBER Board of Directors that accompanies official NBER publications.

(C) 2009 by Darren J. Kisgen and Philip E. Strahan. All rights reserved. Short sections of text, not to exceed two paragraphs, may be quoted without explicit permission provided that full credit, including (C) notice, is given to the source. 
Do Regulations Based on Credit Ratings Affect a Firm's Cost of Capital?

Darren J. Kisgen and Philip E. Strahan

NBER Working Paper No. 14890

April 2009

JEL No. G18,G2,G3

\section{ABSTRACT}

In February 2003, the SEC officially certified a fourth credit rating agency, Dominion Bond Rating Service ("DBRS"), for use in bond investment regulations. After DBRS certification, bond yields change in the direction implied by the firm's DBRS rating relative to its ratings from other certified rating agencies. A one notch better DBRS rating corresponds to a 39 basis point reduction in a firm's debt cost of capital. The impact on yields is driven by cases where the DBRS rating is better than other ratings and is larger among bonds rated near the investment-grade cutoff. These findings indicate that ratings-based regulations on bond investment affect a firm's cost of debt capital.

Darren J. Kisgen

Boston College

140 Commonwealth Av.

Chestnut Hill, MA

Kisgen@bc.edu

Philip E. Strahan

Carroll School of Management

324B Fulton Hall

Boston College

Chestnut Hill, MA 02467

and NBER

philip.strahan@bc.edu 
Credit rating agencies play a central role in financial markets. Previous studies examine whether credit ratings affect yields on a firm's bonds due to the information ratings impart about default risk. Ratings may also affect bond yields because regulations affect the kinds of investors able to hold a firm's bonds or the cost of holding a bond. Relying on an exogenous change in the regulatory status of a particular rating agency, this paper shows that ratingsbased regulations of bond investment affect the cost of debt. We also examine how regulatory status subsequently affects a rating agency's rating decisions.

The Securities and Exchange Commission ("SEC") designates certain rating agencies as Nationally Recognized Statistical Ratings Organizations ("NRSRO(s)”), certifying these agencies as qualified for implementation of various kinds of regulations. Numerous institutions and regulatory bodies rely on ratings from NRSROs for bond investment rules and regulations. These regulations, for example, link the number of institutional investors who may hold bonds (or their capital requirements) to ratings of those bonds granted by an NRSRO (see Kisgen (2006) and Section I.A below for more details). As of January 2003, Standard and Poor's, Moody's and Fitch were the only NRSROs, but in February 2003 the SEC designated Toronto-based Dominion Bond Rating Service (“DBRS”) as a fourth NRSRO. We exploit this unexpected change in DBRS's regulatory status as a quasi-natural experiment to test how ratings can affect bond yields, not merely as a proxy for information but directly through their impact on regulatory enforcement.

We first document that the change in DBRS's status affected yields on the bonds they rate. Firms DBRS rates better than the other NRSROs as of January 2003 experience a decline in their cost of debt after February 2003. By the end of 2003 these firms had experienced a 39 
basis point drop in bond yields compared to firms whose DBRS ratings were the same as the average of the other agencies. To avoid potential selection bias, we consider only bonds rated by DBRS prior to their obtaining NRSRO status. By holding the ratings fixed as of January of 2003, we rule out information-based explanations for the change in yields; since the ratings do not change over time, new information can not explain the change in yields. These tests indicate that the change in regulatory status of DBRS changed the impact of its ratings on a firm's bond yields.

While our tests rule out changes in information affecting yields, it may be that NRSRO status itself increases the value of DBRS ratings after February or 2003. Perhaps SEC certification enhances DBRS' reputation, thereby increasing the credibility of its ratings in the market, even if those ratings do not change. Prior to 2003, DBRS was not a well-established rating agency. Several rating agencies petitioned the SEC for NRSRO status, but only DBRS was granted the accreditation. This vetting out process may indicate that DBRS ratings are higher quality, and thus financial markets may consider ratings provided by DBRS as more informative after February 2003.

To rule out certification, we conduct three additional tests. First, we show that the effect of the change in DBRS's regulatory status affects yields only when they rate a firm better than the other agencies; when the DBRS rating is worse, the cost of capital does not increase. Certification following promotion to NRSRO would imply a symmetric effect on yields. In contrast, the regulatory explanation implies that better ratings would affect bond yields because many of the regulations link investment constraints to the best of the NRSRO ratings (or sometimes the second best). Second, the effect on yields is stronger around the 
investment-grade boundary, where regulations based on ratings are most prevalent and significant. The consequence for an issuer losing its investment grade, for example, can be substantial. When S\&P downgraded General Motors to speculative grade, their bonds fell $8 \%$, and at least one reason provided was that the "downgrade has sent institutions running for the exits...many [of them] have rules that prohibit them from owning non-investment grade debt" (Forbes, 2005). We find that firms with better DBRS ratings around the investment grade cutoff see a reduction in their debt cost of capital of approximately 54 basis points. While we have no direct data on bond holdings, we believe this decline occurs because more investors can hold these bonds, leading gradually to a decline in their yields. Third, we conduct two falsification tests, incorrectly assuming that a change in regulatory status occurred in February 2004 or February 2005. Conducting the same experiments with these alternate dates does not generate any of the results we find for the actual event date. We conclude from this additional evidence that credit ratings affect a firm's cost of capital specifically due to regulations based on ratings.

Having established our main finding, we next test whether DBRS changes its ratings methods when it becomes an NRSRO. These tests are more descriptive in nature, and any interpretation of these results is more speculative. Yet we report these results to provide a more complete description of the impact of this event. After becoming an NRSRO, DBRS expands its market presence and rates more U.S. issuers. Moreover, before becoming an NRSRO, DBRS focused on the high-grade market. After, they increased their emphasis on speculative-grade firms and seem to have begun rating a wider array of firms, just as the incumbent NRSROs do. 
We also find that DBRS ratings become more highly correlated with the ratings of the other NRSROs after February 2003. This ratings convergence occurs because the relationship between issue size and lagged yields and the DBRS rating shifts. Prior to becoming an NRSRO, large issues and bonds with a relatively high yield were more likely to be rated better by DBRS than the other agencies. This effect disappears after DBRS becomes an NRSRO. Also, when we control for the effect of size and yields, the ratings convergence result disappears. DBRS seems to have rated large and higher-yield firms more generously, perhaps trying to win market share. After February 2003, this incentive may have been dominated by the incentive to provide more credible ratings.

Our study extends recent papers testing how ratings affect bond yields. Kliger and Sarig (2000) use a similar quasi-natural experiment approach to test how information from ratings affects yields. They compare bond yields before and after Moody's added modifiers in April 1982, increasing the fineness of their ratings measure (e.g., an A-rated firm then became an A1, A2 or A3 rated firm). They find that the change in information content decreased yields of bonds rated at the high end of the scale relative to bonds rated at the low end. Our study complements theirs. Like Kliger and Sarig (2000), we exploit a natural experiment, but our set-up varies the regulatory status of the rating agency holding information constant, exactly the reverse of their empirical design. Consistent with our study, Bongaerts, Cremers and Goetzmann (2008) find that Fitch ratings - the third NRSRO - matter mainly for regulatory reasons. While they are not able to exploit a natural experiment, they find that firms are more likely to have a Fitch rating when S\&P and Moody's are on opposite sides of the investment grade margin, and that a positive Fitch rating only comes with lower yields for bonds near 
investment grade. Taken together, these studies indicate that ratings affect a firm's cost of capital for both information and regulatory reasons. ${ }^{1}$

The rest of this paper is organized as follows. In Section I we establish the main hypothesis of the paper and provide institutional details regarding rating regulations. In Section II we discuss the contribution of the paper relative to existing literature. In Section III we provide the empirical tests of the paper. In Section IV we conclude.

\section{Hypothesis Development and Institutional Background}

\section{A. Ratings-Based Regulations and Debt Cost of Capital}

The cost of debt capital for a firm is fundamentally determined by the risk free cost of capital and a spread due to estimated default risk. If the supply of debt capital from investors is infinitely elastic at the correct rate of interest, regulatory restrictions for certain investors on bond investment should not affect a firm's cost of capital. However, if the supply of capital is not infinitely elastic, regulations which affect the cost to investors of investing in a particular bond class or restrictions placed on investors in certain bonds may affect a firm's cost of

\footnotetext{
${ }^{1}$ Our study also generally relates to previous literature which examines the information content of ratings, and whether ratings affect financing and investment decisions. Hand, Holthausen and Leftwich (1992) find statistically significant negative average excess bond and stock returns upon the announcement of bond rating downgrades. Ederington, Yawitz and Roberts (1987) and West (1973) find that credit ratings are significant predictors of yield to maturity. Ederington and Goh (1998) show that credit rating downgrades result in negative equity returns. Faulkender and Petersen (2006) and Sufi (2009) find that having a rating increases a firm's leverage (and they conclude this is due to increased access to capital). Kisgen (2006 and 2009) finds that credit ratings affect firm capital structure decisions.
} 
capital. $^{2}$ For example, yields on bonds with higher regulatory costs will be higher to compete with bonds that have lower regulatory costs, ceteris paribus. By affecting a firm's cost of capital, these regulations may materially affect a firm's financing and investment decisions.

Many investment rules and regulations are based on a bond's credit rating as provided by rating agencies. Regulations based on credit ratings began as early as 1931, when banks were required to mark-to-market lower rated bonds. In 1936, the U.S. Treasury Department then issued a ruling that banks could not invest in securities that are "distinctly and predominantly speculative" according to a "designated standard" which must be "supported by not less than two rating manuals." Following this, banks went through a significant reorganization with the ultimate result being an increase in spreads between BBB rated and BB rated bonds. In 1989, Savings and Loans were prohibited from investing in junk bonds such that they could not hold any junk bonds by 1994. In 1993, the Basle Committee on Bank Supervision proposed in its market risk guidelines that internationally active commercial banks dealing in securities should hold extra capital against their non investment-grade bond inventories as well.

Insurance company investment is also affected by regulations based on ratings. In 1951, the National Association of Insurance Commissioners (NAIC) established the Securities Valuation Office (SVO) to assign risk ratings to bonds held in the investment portfolios of insurance companies. These risk ratings are largely determined using credit ratings, whereby the SVO assigns 6 quality ratings that correspond to the ratings of the major agencies. Firms that are rated $\mathrm{A}$ or above get a value of 1 , firms that are $\mathrm{BBB}$ get a value of 2 , BB get a $3, \mathrm{~B}$ a

\footnotetext{
${ }^{2}$ Restrictions on investment might also affect a bond's liquidity, which would affect its cost of capital even if the supply curve was infinitely elastic. Regulations affect firm disclosure as well; in 1982, the SEC allowed less detailed disclosure requirements for issuers of investment grade securities relative to non-investment grade.
} 
4, any $\mathrm{C}$ level gets a 5 , and any $\mathrm{D}$ rating gets a 6 . The insurance company's capital requirements are determined by these ratings, thus higher capital requirements are imposed on insurers when their portfolios contain bonds with lower ratings, so the riskier securities are more expensive for insurance companies to own. At this time, the NAIC began equating the term "investment grade" to bonds with a Baa-rating or better. Investment grade bonds were therefore bonds with a rating of Baa or BBB or higher by Moody's or S\&P's, respectively, and junk (or high-yield) bonds are those with rating of Ba or BB or lower by Moody's or S\&P's, respectively. In 1990, the NAIC further tightened guidelines for junk bond investment by life insurance companies.

Several additional institutions are affected by regulations based on ratings. SEC Rule 2a-7 states that money market mutual funds are required to limit investments in bonds rated less than A+, and commercial paper rated less than A1 (see Kisgen (2007)). In 1975, the SEC adopted Rule 15c3-1 that set forth broker-dealer haircut requirements that were a function of the credit ratings of those securities. Through this rule, the SEC applied a net capital rule whereby credit ratings became the basis for determining the percentage reduction in the value ("haircut") of bonds owned by broker-dealers for the purpose of calculating their capital requirements. Many trustees use credit ratings to give guidelines to fund managers as well. Pension funds also often place limits on the amount of a portfolio that can be invested in junk bonds, and in 1988 the Department of Labor instituted a regulation permitting pension fund investment in asset-backed securities only rated A or better. Investment grade bond mutual funds can only hold up to $5 \%$ of assets in non-investment grade bonds but must sell any security if it falls below a B rating. The Eurobond and Asset Backed Securities markets often require a certain rating for a firm to participate in that market. California state regulations 
prohibit California-incorporated insurance companies from investing in bonds rated below single-A. In this paper, we investigate whether these extensive rules and regulations affect a firm's cost of capital.

\section{B. Nationally Recognized Statistical Ratings Organizations (NRSROs)}

The regulations discussed in the previous section are all based on credit ratings. Without further clarification for which rating agency's ratings could be used for these regulations, arbitrary firms could be established to provide specious "ratings" to circumvent the effects of these regulations. Recognizing this issue, in 1975 the SEC designated certain ratings agencies as "nationally recognized statistical rating organizations" (NRSROs), which indicated that they are qualified for use in regulations. The three existing rating agencies at the time Moody's, S\&P, and Fitch — were immediately "grandfathered" into the NRSRO category. Consequently, only NRSRO ratings were valid for the determination of broker-dealers' capital requirements, and then bank and insurance company regulators adopted the NRSRO distinction, as did other financial regulators. The SEC then decided to use it again for money market mutual funds regulations. The SEC acknowledges, "Although we originated the use of the term NRSRO for a narrow purpose in our own regulations, ratings by NRSROs today are used widely as benchmarks in federal and state legislation, rules issued by other financial regulators, in the United States and abroad, and private financial contracts." (SEC, 2003)

A rating agency must apply to the SEC to obtain NRSRO status. The NRSRO process has been criticized for a lack of transparency regarding the qualifications and process of obtaining NRSRO status and for perhaps inefficiently limiting the number of certified rating agencies, 
thereby stifling competition. Firms that were rejected for NRSRO status complained that the process was unfair and stifled competition. The SEC did not originally provide a statement of the qualifications for being designated as an NRSRO, and in 1997, when the agency proposed regulations that would define an NRSRO, it did not enact final regulations. The primary guidance for whether a firm would qualify was that the firm should be "nationally recognized" in the United States and be an issuer of "credible and reliable ratings". From 1975 to 2000, the SEC designated only four additional firms as NRSROs, but several mergers led to the number of NRSROs reverting to the original three (Moody's, S\&P, and Fitch) by 2000. This changed however in 2003, when the SEC granted DBRS NRSRO status, which is the basis for our study.

The Credit Rating Reform Act of 2006 subsequently required the SEC to establish clearer guidelines for which firms would qualify for NRSRO status (see Cantor and Packer (1994) and White (2007)). Since then, five additional firms have been granted NRSRO status: Japan Credit Rating Agency, Ltd., Ratings and Investment Information, Inc., LACE Financial, Realpoint LLC, and Egan-Jones Ratings Company. The total of NRSROs as of January 2009 was ten (A.M. Best, a rating agency primarily focused on the insurance industry, was granted NRSRO status in 2005). The SEC continues to consider the implications of the designation, and with recent regulations, has tried to minimize the impact of ratings. Our study speaks directly to one of the primary dimensions in which these regulations are material for a firm. 


\section{Credit Rating Literature and Relative Contribution}

Significant literature examines the information content of ratings. Credit ratings might impact a firm's bond yields if they provide non-public information regarding a firm's probability of default. Rating agencies may receive significant sensitive information from firms that is not public, as firms may be reluctant to provide information publicly that would compromise their strategic programs, in particular with regard to competitors. Credit agencies might also specialize in the information gathering and evaluating process and thereby provide more reliable measures of the firm's creditworthiness. Regulation FD also excludes rating agencies, such that rating agencies continue to be allowed to receive non-public information.

The literature examining the information content of ratings is comprised of three main approaches: tests examining the relationship between the level of a firm's bond yield and ratings, tests examining the relationship between changes in yields and changes in ratings, and tests utilizing a natural experiment to identify the impact of ratings on bond yields. These studies typically do not make a distinction between regulatory versus information based explanations for the impact on yields, although most emphasize the information aspect. For example, Hand, Holthausen and Leftwich (1992) find statistically significant negative average excess bond and stock returns upon the announcement of downgrades of straight debt. Ederington, Yawitz and Roberts (1987) and West (1973) find that credit ratings are significant predictors of yield to maturity beyond the information contained in publicly available financial variables and other factors that would predict spreads. Ederington and Goh (1998) show that credit rating downgrades result in negative equity returns and that equity analysts tend to revise earnings forecasts "sharply downward" following the downgrade. They further 
conclude that this action is a result of the "downgrade itself - not to earlier negative information or contemporaneous earnings numbers." ${ }^{33}$ Becker and Milbourn (2009) examine the change in ratings quality when Fitch decides to rate a firm, in addition to Moody's and S\&P. Kliger and Sarig (2000) rely on a natural experiment to examine the informational impact of ratings on yields. In April 1982, Moody's added modifiers to their ratings, increasing the fineness of their ratings measure (e.g., an A-rated firm then became an A1, A2 or A3 rated firm). This represents an exogenous change in the information provided by Moody's ratings, holding its regulatory status constant. Kliger and Sarig (2000) find that this change impacts bond yields in the direction implied by the modification. Tang (2009) extends this work by relying on the same event for additional tests.

Other papers examine the impact of ratings on the supply of debt capital. Faulkender and Petersen (2006) and Sufi (2009) find that firms with bond or bank-loan ratings issue more debt or have more leverage. Since firms choose to be rated, Faulkender and Peterson (2006) use instrumental variables for the existence of a bond rating for identification. Sufi (2009) relies on firm fixed effects and control variables for identification. Our study differs from these studies by looking at the regulatory impact of different levels of ratings instead of the impact of having rating, we look at the impact on yields not leverage, and we rely on a natural experiment for identification. Our study also pinpoints the direct impact of regulations, whereas these other studies examine general supply of capital effects.

\footnotetext{
${ }^{3}$ Cantor and Packer (1997) also show that the average credit rating is more correlated with yields than that of either agency alone, while Morgan (2002) shows that hard-to-value firms such as banks (especially trading banks) are more likely to receive a split rating than other firms.
} 
Finally, recent literature also focuses on the impact of ratings on corporate leverage. Kisgen (2006) finds that firm near a change in credit rating are more likely to undertake leverage reducing activity. Kisgen (2009) finds that after a firm is downgraded, a firm is more likely to reduce leverage, presumably to regain a previous rating target. These effects are shown to be stronger at the investment grade cutoff, and also stronger for firms which see downgrades in their commercial paper ratings, both of which are consistent with the significance of regulations. To the extent that we find that regulations based on ratings affect a firm's cost of capital, this paper provides justification for the corporate behavior documented in this previous work.

Our contribution lies fundamentally with our empirical design which allows us to identify specifically the regulatory impact of ratings. The change in regulatory status of DBRS should have no impact on the information content of DBRS ratings that were assigned prior to DBRS receiving that status. Even after DBRS received NRSRO status, the information impact of the change in status should be small. DBRS might be able to obtain better access to firms after receiving DBRS certification from the SEC, but it is unclear to what extent that would manifest. Our empirical tests also rely on the ratings prior to February 2003 to examine this affect, so the identification issues raised in Faulkender and Petersen (2006), Sufi (2009) and Becker and Milbourn (2009) are mitigated. Our study is the first to document that regulations based on rating affect a firm's cost of capital. 


\section{Empirical Results}

\section{III.A. Data and Summary Statistics}

Bond ratings and yield data come from Bloomberg from 2001-2005. We obtain a firm's DBRS, S\&P, Moody's and Fitch ratings, and the yields on its bonds for each month. The sample is constrained to include only non-financial firms with a DBRS rating where we can observe monthly bond yields. For the main empirical tests of the paper, the sample is further constrained to include only bonds rated by DBRS as of January 2003, one month prior to their winning NRSRO status. This sub-sample consists of 42 firms and 90 bonds (when a firm has multiple bonds, we include all of them and then cluster standard errors by firm). We merge these observations to Compustat to obtain firm specific information, such as size and leverage.

Tables 1-3 report summary statistics for the sample of firms rated by DBRS. Table 1 reports the number of issuers and bonds in each year of our sample from 2001-2005, as well as the distribution across rating bins. Notably, DBRS increases its market share considerably after 2003, gains access to the U.S. market, and expands across to whole spectrum of the ratings distribution. For example, in 2001 almost $90 \%$ of their business focused on Canadian issuers. By 2005 this share had fallen to about 50\%. After obtaining NRSRO status, the number of firms rated by DBRS increases from 46 in 2002 to 165 in 2005 (the total number of firms actually rated by DBRS is higher, since we place restrictions for inclusion in our sample). The distribution of firms rated by DBRS also changes significantly after they obtain NRSRO status. Of the firms rated by DBRS, $27.1 \%$ have a BB or BBB rating prior to February 2003, 
compared to $48.8 \%$ for S\&P. After becoming and NRSRO, $46.7 \%$ of DBRS's newly rated issuers have a $\mathrm{BB}$ or $\mathrm{BBB}$ rating, compared to $52.8 \%$ for $\mathrm{S} \% \mathrm{P}$. Thus, DBRS chooses to rate more low-quality firms and more firms near the investment grade distinction after becoming an NRSRO.

Table 2 reports statistics on the bonds rated by DBRS, Moody's and S\&P. Since Moody's and S\&P rate virtually all bonds, this sample is effectively the sample of firms rated by DBRS that we can identify in Bloomberg. The mean rating for bonds rated by DBRS increases after DBRS becomes an NRSRO, indicating that DBRS rates on average lower quality issuers after obtaining NRSRO status (a bond's rating is cardinalized for these tables, such that a AAA bond is coded with a value of $1, \mathrm{AA}+$ is 2 , etc.). DBRS also appears to rate firms somewhat more favorably than the other rating agencies at all times, and that propensity increases slightly after NRSRO status. However, as we see below, this relationship may reflect some omitted characteristic of a bond which DBRS merely weights differently from the other agencies.

Table 3 compares characteristics of firms rated by DBRS versus the sample of firms rated by S\&P, using Compustat data. DBRS-rated firms are about three times larger than the average of firms rated by S\&P. DBRS also rates a disproportionate number of mining and construction firms, which reflects its Canadian headquarters. No significant differences exist for leverage or the percentage of tangible assets for firms rated by DBRS compared to those rated by $S \& P$. 


\section{III.B. Main Tests}

Table 4 reports results from the first main tests of the paper (columns $1 \& 2$ ). We test the following cross-sectional regressions for each of the ten months after DBRS obtains NRSRO status. The months, T, range from March to December 2003.

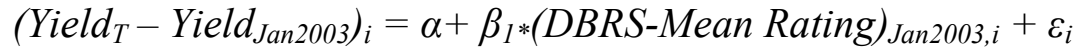

For each test, the dependent variable is the yield on a firm's bond for the indicated month minus its yield on January 2003, the month prior to DBRS obtaining NRSRO status. The intercept in (1) controls for changes in bond spreads between month T and January of 2003. The explanatory variable equals the bond's DBRS rating as of January 2003 minus the mean rating from Moody's and S\&P as of January 2003. ${ }^{4}$ Our identification strategy is designed to focus solely on the regulatory effects on yields, so the dependent variable captures the change in the mean NRSRO rating (including DBRS) that occurs only because of the change in DBRS's status. If DBRS rates a bond the same as the other agencies, then becoming an NRSRO has no impact on the average rating the bond receives (and our explanatory variable equals 0). If DBRS differs from the other agencies, however, then a firm's average NRSRO rating will change as a result of the change in DBRS's regulatory status. Since we hold the ratings constant at their predetermined level (January 2003), the variable captures the change in a firm's average NRSRO rating that occurs solely because of the change in DBRS's status.

\footnotetext{
${ }^{4}$ We report our results using the average of Moody's and S\&P because almost all of our bonds are rated by both of the two major NRSROs. In contrast, only 5 of the 90 bonds are rated by Fitch. We have, however, also estimated equation (1) using the average across all three of the NRSRO when the Fitch rating is available and the results are very similar to those reported here. See Table 7 and the description below.
} 
Any information provided by a firm's rating in January 2003 should be incorporated in the yield as of January of 2003. ${ }^{5}$ Each cross-sectional test includes bonds for the 42 firms with DBRS ratings as of January 2003. If DBRS ratings affect a firm's cost of capital once DBRS obtains NRSRO status, we expect $\beta_{1}$ to be greater than 0 , implying a better DBRS rating leads to lower yields and a worse rating leads to a higher yield. The null hypothesis is that the regulatory status of DBRS is not important for a firm's cost of capital, implying $\beta_{1}=0$.

The results indicate that the difference in a bond's DBRS rating from the other agencies significantly affects its yield once DBRS obtains NRSRO status (Table 4). By December 2003, yields change by 16 basis points per ratings-notch difference between DBRS and the other agencies. $^{6}$ Given the structure of the empirical design, it's difficult to explain this change in yield with anything other than this particular event. This change in yield however is not immediate. For example, three months after DBRS obtains NRSRO status, the yield change is only 5 basis points, and not statistically distinguishable from zero. The gradual increase in magnitude makes sense given the regulatory explanation for these results, and given the relative illiquidity of the corporate bond market. Investors may not immediately adjust to the change in regulatory status of NRSRO, and therefore the full effect is incorporated slowly as investors modify their portfolios. An information-based explanation would imply a more immediate impact on yields.

\footnotetext{
${ }^{5}$ A change in the NRSRO rating stemming from an increase or decrease in default risk for a bond could also be correlated with yield changes. As a robustness test, we have also estimated equation (1) controlling for this effect by adding the change in the mean NRSRO rating between month $T$ and January 2003. This variable does not enter the regression with a significant coefficient, and the effect of the pre-existing DBRS rating remains economically and statistically significant. See Table 7 and the description below.

${ }^{6}$ Although we have clustered at the issuer level, we have also estimated the model using issuer-level averaged data with non-clustered, robust standard errors (so $\mathrm{N}=42$ rather than 90 ). In this model the point estimate increases from 16 to 27 basis points at the 10-month horizon, with a T-statistic of 2.52 (from 2.17).
} 
Table 4 also reports our falsification tests (columns 3-6). We incorrectly pretend that a change in regulatory status occurs in February of 2004 or February of 2005, and re-estimate equation (1). The sample for each test includes all DBRS-rated firms as of January of the particular year. These tests do not generate the same results. The difference in rating between DBRS and the other agencies has no impact on yields after these artificial event dates. These tests reinforce that the previous results are unique to February 2003, the month that DBRS was awarded NRSRO status.

\section{III.C. Regulation, not certification}

So far we have established that the change in regulatory status strengthened the market impact of the DBRS rating. Is that due to regulatory effects of ratings, or SEC certification of DBRS? Market participants might view ratings from DBRS as more credible signals of default risk because of a rigorous SEC vetting process. The remaining tests of this section are designed to clarify whether these results are indeed specific to ratings-based regulations.

In Table 5, we examine whether the yield impact is larger when the DBRS rates a firm more favorably versus when it rates a firm worse. If the change in yield identified in Table 4 is due to certification, DBRS ratings should become uniformly more informative after February 2003. This additional information content would thus affect yields symmetrically, decreasing yields when DBRS rates better and increasing them when they rate worse. The regulatory channel predicts a significant asymmetry in the yield effect, however, because most regulations depend on a minimum rating from one (or sometimes two) NRSRO. For example, if Moody’s and S\&P rate a firm investment grade already, a non-investment grade rating from 
DBRS should have little regulatory impact. On the other hand, if Moody's rates a firm investment grade and S\&P does not, then an investment grade rating from DBRS could significantly expand the pool of investors willing to hold these bonds and thus lower the yield. To examine this implication, we extend the model above, as follows:

$\left(\text { Yield }_{T}-\text { Yield }_{\text {Jan }}\right)_{i}=\alpha+\beta_{2} *$ Better $^{*}(\text { DBRS-Mean Rating })_{J a n, i}+\beta_{3} *$ Worse $^{*}($ DBRS-Mean Rating) Jan,i $+\varepsilon_{i}$

This test is identical to the test of equation (1) except for the introduction of the dummy variables Better and Worse. Better equals one if the DBRS rates a firm better than the mean rating of the other agencies; Worse equals one if the DBRS rates a firm worse. If the DBRS rating is equal to the mean rating of the other agencies, the value of "DBRS-Mean Rating" is zero and thus the Better and Worse dummies are not live variables. The regulatory explanation implies that the coefficient on $\beta_{2}$ is greater than zero and that $\beta_{2}>\beta_{3}$. The certification explanation implies that both $\beta_{2}$ and $\beta_{3}$ are both greater than zero (and equal to each other).

The results of Table 5 indicate a significantly higher impact on yields from a DBRS rating that is better than the mean rating than if it is worse. A one notch better rating from DBRS implies a 39 basis point reduction in a firm's debt cost of capital by December 2003. The relative difference between a better DBRS rating versus a worse DBRS rating is 42 basis points (39-(-3)). The hypothesis that $\beta_{2}$ and $\beta_{3}$ are equal is rejected at the $1 \%$ level in all months six months or later than the event date. Furthermore, the impact on yields from a worse DBRS rating is insignificant in all months (in month seven it is 'significant' but in the 
wrong direction). The evidence in this table strongly support the notion that ratings-based regulations affect a firm's cost of capital.

In Table 6, we examine whether the impact on yields from DBRS becoming an NRSRO is larger for firms rated near the investment-grade/speculative-grade cutoff. Many of the regulations outlined in Section I are concentrated or are more severe if a firm's rating is below investment grade. Therefore, a firm near the investment grade margin can benefit more from the change in DBRS's status than a firm that is very highly rated (A or above), or very poorly rated (B or worse). Having DBRS rate better than the other NRSROs accrues large benefits to firms near an upgrade to investment grade or to those near a downgrade to speculative grade. To examine these firms, we create a dummy variable, "Near Investment Grade", which equals one if the firm is rated $\mathrm{BBB}$ or $\mathrm{BB}$ (Kisgen (2006) uses a similar measure)). If regulations are insignificant for a firm's cost of capital, we would expect to see no incremental difference for this group of firms. We interact the DBRS relative rating with a "Near Investment Grade" dummy variable to test if its effects are larger for these marginal firms.

Table 6 shows that the effects are concentrated among firms near investment grade when DBRS rates better than the other agencies. The magnitude is both statistically and economically significant, with nearly a 55 basis point reduction in yields for firms with a better DBRS rating that are near the investment grade distinction (and a 16 basis point decline for better firms that are away from the investment grade margin). The large magnitude of the estimated effect presumably reflects the high spread between the investment grade and speculative grade markets during our sample, which averaged about 250 basis points in 2003 (BBB v. BB). Some caution should also be taken with the interpretation of these results, since 
the subsample of firms near the investment grade cutoff with a DBRS rating which is better than the average rating of other rating agencies is only 9 firms (and 15 bonds). The evidence nevertheless underscores the importance of regulations for a firm's cost of capital.

\section{III.D. Robustness Tests}

Table 7 reports three robustness tests. Each column has one cross-sectional regression, inverting the presentation format relative to Tables 4-6. Column 1 reports the benchmark regression for comparison (the model in the last row of Table 6), and the subsequent columns

report the robustness tests. All of these regressions are based on the cross-sectional regression at the 10-month horizon. First, we redefine the relative rating variable using the all three NRSROs - Moody's, S\&P and Fitch - to define the mean NRSRO (column 2). Second, we introduce four control variables: the initial (January 2003) mean NRSRO rating, the change in the mean NRSRO rating (December - January), the log of the size of the bond, and an indicator for Canadian issuers (column 3). Third, we change the dependent variable from the absolute yield change to the percentage change in yield, with and without the four new control variables (columns 4 \& 5).

Our results remain similar across all three robustness tests. Introducing the Fitch rating has very little impact because only 5 bonds are affected by this change; if anything the results get slightly stronger. Introducing the four control variables strengthens the effect of the DBRS rating for the firms near the investment-grade margin (slightly) and weakens the effect for the other bonds (again only slightly). Adding the initial level of the rating controls for the possibility that spreads within the corporate bond market changed; adding the change in the mean NRSRO rating controls for the possibility that some of the yields change due to 
changes in credit quality; adding the log of issue size controls for the possibility that larger issues experienced a change in yields compared to smaller issues; and adding the Canadian indicator controls for the possibility that Canadian firms experienced yield changes relative to American issuers. In fact, we do find significance on both the initial rating and the Canadian indicator $\left(\mathrm{R}^{2}\right.$ rises to about $\left.50 \%\right)$, but adding these controls has very little effect on our main result.

\section{III.E. Does DBRS change it ratings methods?}

In Table 8 we test whether DBRS changes the way it rates bonds. For these tests, we use the sample of bonds rated by DBRS prior to becoming an NRSRO (columns 1-3), and we then expand the sample to include all DBRS-rated bonds before and after February 2003 (columns 4-6). By including all bonds, we lose the clean identification of the tests of the previous section. However, including them allows us to examine the behavior of DBRS before and after they receive NRSRO status. While causality is hard to sort out in these tests, we report them to paint a more complete picture of this event.

The dependent variable for the tests in Table 8 equals the DBRS rating in a particular bondmonth. We order the ratings from 1 (AAA) to $2(\mathrm{AA}+)$ all the way up to $20(\mathrm{CC})$. We report both fixed effects OLS regressions (columns 1 and 4), and, since there are no natural units for credit ratings, ordered Logits. The independent variables are bond or issuer characteristics, measured one month prior to the month for the DBRS rating. These variables include the mean rating issued by S\&P and Moody's (measured on the same numerical scale), the log of the issue size, the yield of the issue, an indicator for whether the bond was issued by a 
Canadian firm, an indicator for bonds near the investment grade cutoff, and an indicator for whether the time period was after DBRS receives NRSRO status. The yield of the issue and the rating of the issue are of course correlated; moreover, it is difficult to sort out the causality between yields and ratings because ratings changes both lead and lag yield changes. Hence we report results with and without the yield.

The first and fourth columns of Table 8 reports the stripped down OLS model with bond fixed effects, the mean rating by the longstanding NRSROs, a post-NRSRO indicator, and their interaction. A coefficient of one on the mean rating variable suggests that DBRS follows rating changes by the other agencies one-for-one. The actual coefficient of 0.52 ( 0.56 with all bonds) indicates that changes in ratings are significantly related for DBRS compared to other firms, but that DBRS also makes changes independent from the other agencies. The coefficient on the mean rating variable interacted with the Post-NRSRO indicator is positive and significant, meaning that changes in ratings from DBRS become more tightly linked to those of the other NRSROs after February 2003. So, DBRS converges toward the other NRSROs after their change in status.

Next, we drop the bond fixed effects and replace them with bond characteristics to help identify why DBRS diverges from the other agencies. We report ordered Logits, which are estimable (and preferred to OLS) in the absence of the fixed effects. DBRS tends to provide a more favorable rating to large issues prior to gaining NRSRO status, but this preference falls in the post-NRSRO period. In the sample with all bonds, the sum of the direct and interaction terms is not statistically significant, suggesting that there is no impact of issue size after DBRS becomes an NRSRO. (Since the model conditions on the other NRSRO ratings, the 
result means that DBRS does not place greater weight on size than the other agencies.) DBRS also seems to provide Canadian issuers more favorable ratings in both periods. We find no evidence that DBRS rates firms near the investment grade cutoff more favorably, either before or after becoming an NRSRO. Having shown that DBRS rates more firms near the investment grade cutoff in the post period, one might expect that they would also systematically provide them with better ratings. This does not appear to be the case. We conclude that although there is more demand for DBRS ratings from firms near the investment grade cutoff, DBRS maintains its objectivity when rating them.

In columns 3 and 6, we add the bond yield to the models. Prior to February 2003, firms with higher bond yields receive better ratings from DBRS, controlling for the firm's rating from the other agencies. This result could reflect demand from firms who believe their bond yields do not reflect fundamentals, and who therefore seek another rating. Or, DBRS may market their services to firms whose ratings appear too conservative. Regardless, it suggests a contrarian style prior to NRSRO status. In the post NRSRO period, this relationship disappears completely. The coefficient on the yield interacted with the post period $(0.69)$ negates the pre NRSRO effect $(-0.75)$, and the sum of these effects is not significant in either sample.

\section{Conclusions}

We have shown that regulations constraining bond investment affect yields and thus firms' cost of capital. Our strategy exploits a quasi-natural experiment: in February 2003, the SEC deemed DBRS a 'Nationally Recognized Statistical Rating Organization'. Ratings granted by 
such NRSROs are used to determine capital requirements for holders of bonds such as insurance companies, banks and broker-dealers. Moreover, some investors will not hold bonds unless they are rated investment grade by one or more of the NRSROs. We find that bond yields fall for firms that DBRS rates more favorably than the other NRSROs after the SEC's decision. The decline shows up asymmetrically. There is no increase in yields for bonds that DBRS rates relatively unfavorably. Moreover, the effects are larger around the investment-grade cutoff, where the effects of regulatory constraints are most binding. Hence, we conclude that bond regulations affect yields. The result suggests that simple tradeoff theories, where firm balance financial distress costs against tax benefits, are too simple. Our results imply, for example, that a firm losing its investment grade would suffer a larger increase in its cost of capital than would be expected solely from the implied increase in probability of distress.

We also provide some descriptive evidence about DBRS' ratings methods before and after becoming an NRSRO. These results are harder to interpret causally, particularly correlations between ratings and yields. Nevertheless, the data suggest that DBRS rates bonds more like the other major agencies after becoming an NRSRO. In 2006 Congress passed legislation improving the transparency and lowering the cost of becoming an NRSRO. Five new agencies have recently become NRSROs, raising the total number to nine from three less than ten years ago. This change in structure may radically alter the incentive of these agencies, especially because, as we have shown, ratings granted by them can change firms' cost of capital even absent changes in risk. 


\section{REFERENCES}

Becker, B. and T.T. Milbourn, "Reputation and Competition: Evidence from the Credit Rating Industry", working paper.

Bongaerts, Dion, Martijn Cremers and William Goetzmann, 2008, "Multiple Ratings and Credit Spreads," Yale ICF Working Paper no. 08-27.

Cantor, Richard and Frank Packer, 1994, “The Credit Rating Industry,” Federal Reserve Bank of New York Quarterly Review 19(2), 1-26.

Cantor, Richard and Frank Packer, 1997, "Split Ratings and the Pricing of Credit Risk," Journal of Fixed Income 7(3), 72-82.

Ederington, L. H.; J. B. Yawitz; and B. E. Roberts. "The Informational Content of Bond Ratings", The Journal of Financial Research 10 (1987), 211-226.

Ederington, L. H., and J. C. Goh. "Bond Rating Agencies and Stock Analysts: Who Knows What When?", Journal of Financial and Quantitative Analysis 33 (1998), 569-585.

Faulkender, M., and M. Peterson, 2006, Does the source of capital affect capital structure?, Review of Financial Studies.

Forbes, “GM’s Preferred Stock Clearance Sale”, March 24, 2005.

Hand, J. R. M.; R. W. Holthausen; and R. W. Leftwich. "The Effect of Bond Rating Agency Announcement on Bond and Stock Prices", Journal of Finance 47 (1992), 733-752.

Kisgen, Darren J., 2006, “Credit Ratings and Capital Structure”, Journal of Finance 61, 1035-1072.

Kisgen, Darren J., 2007, “The Influence of Credit Ratings on Corporate Capital Structure Decisions", Journal of Applied Corporate Finance.

Kisgen, Darren .J., 2009, “Do Firms Target Credit Ratings or Leverage Levels?”, Journal of Financial and Quantitative Analysis, forthcoming.

Kliger, D., and O. Sarig, 1999, The information value of bond ratings, Journal of Finance, 55, 2879-2903.

Morgan, Donald P., 2002, "Rating Banks: Risk and Uncertainty in an Opaque Industry," American Economic Review 92(4), 874-888.

SEC, "Rating Agencies and the Use of Credit Ratings under the Federal Securities Laws", 2003. 
Sufi, A., "The Real Effects of Debt Certification: Evidence from the Introduction of Bank Loan Ratings", Review of Financial Studies, forthcoming.

Tang, T., 'Information asymmetry and firm's' credit market access: Evidence from Moody's credit rating format refinement", Journal of Financial Economics, forthcoming.

West, R. R., 1973, Bond ratings, bond yields and financial regulation: some findings, Journal of Law and Economics 16, 159-168.

White, L. J., “A New Law for the Bond Rating Industry - For Better or For Worse?”, New York University Law and Economics Working Papers, 2007. 


\section{Table 1: Sample Description}

This table reports the number of observations over time for which we can observe the DBRS rating, the yield on the bond and the average rating by the other three NRSROs, and the ratings distributions using the DBRS scale.

\begin{tabular}{|c|c|c|c|c|c|}
\hline Year & $\begin{array}{c}\text { Number of } \\
\text { observations }\end{array}$ & $\begin{array}{c}\text { Number of } \\
\text { Bonds }\end{array}$ & $\begin{array}{l}\text { Number of } \\
\text { Issuers }\end{array}$ & $\begin{array}{c}\text { Fraction } \\
\text { Canadian Issuers } \\
\end{array}$ & \\
\hline 2001 & 314 & 57 & 32 & $87 \%$ & \\
\hline 2002 & 818 & 113 & 46 & $78 \%$ & \\
\hline 2003 & 1,534 & 235 & 73 & $71 \%$ & \\
\hline 2004 & 3,878 & 541 & 119 & $57 \%$ & \\
\hline 2005 & $\underline{8,224}$ & $\underline{877}$ & $\underline{165}$ & $51 \%$ & \\
\hline Total & 14,768 & 1,823 & 435 & & \\
\hline & & & \multicolumn{3}{|c|}{ After NRSRO } \\
\hline Distribution of DBRS-rated bonds & Before NRSRO & $\begin{array}{c}\text { S\&P Ratings } \\
\text { Distribution 2001- } \\
02\end{array}$ & $\begin{array}{l}\text { Existing } \\
\text { Customers }\end{array}$ & New Customers & $\begin{array}{c}\text { S\&P Ratings } \\
\text { Distribution 2003- } \\
05\end{array}$ \\
\hline$\overline{\mathrm{AAA}}$ & $5.8 \%$ & $1.1 \%$ & $3.4 \%$ & $7.1 \%$ & $0.9 \%$ \\
\hline AA & $7.7 \%$ & $4.7 \%$ & $4.0 \%$ & $5.4 \%$ & $3.9 \%$ \\
\hline A & $59.5 \%$ & $20.3 \%$ & $49.2 \%$ & $38.3 \%$ & $18.3 \%$ \\
\hline BBB & $26.9 \%$ & $28.4 \%$ & $43.4 \%$ & $36.6 \%$ & $30.1 \%$ \\
\hline BB & $0.2 \%$ & $20.4 \%$ & $0.0 \%$ & $10.1 \%$ & $22.7 \%$ \\
\hline B & $0.0 \%$ & $18.5 \%$ & $0.0 \%$ & $2.4 \%$ & $19.9 \%$ \\
\hline CCC and worse & $0.0 \%$ & $6.6 \%$ & $0.0 \%$ & $0.2 \%$ & $4.2 \%$ \\
\hline
\end{tabular}


Table 2: Summary Statistics

This table reports simple summary statistics for yields and ratings for our sample of bonds with a rating from all three agencies - Moody's, S\&P and DBRS.

Before DBRS became an NRSRO After DBRS became an NRSRO

\begin{tabular}{|c|c|c|c|c|c|}
\hline & & ) & 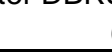 & 42) & \\
\hline & Mean & $\begin{array}{l}\text { Standard } \\
\text { Deviation }\end{array}$ & Mean & $\begin{array}{l}\text { Standard } \\
\text { Deviation }\end{array}$ & $\begin{array}{c}P \text {-value }{ }^{1}:(H O: \\
\text { Pre }==\text { Post })\end{array}$ \\
\hline Yield to Maturity (\%) & 6.43 & 0.96 & 5.23 & 1.07 & 0.00 \\
\hline Fraction rated the same by all agencies & $73.0 \%$ & - & $64.0 \%$ & - & 0.66 \\
\hline Absolute rating difference (Best - Worst) & 0.30 & 0.53 & 0.52 & 0.83 & 0.44 \\
\hline Mean Rating (S\&P, Moody's \& Fitch) - 1 means AAA, 2 means AA, ... & 6.29 & 2.30 & 6.92 & 3.12 & 0.02 \\
\hline DBRS rating - Mean Rating & -0.17 & 1.04 & -0.25 & 0.84 & 0.08 \\
\hline
\end{tabular}

${ }^{1}$ The p-value tests the null that the mean in the two periods is the same. The statistic is built controlling for bond-level fixed effects and clustering the data by issuer. 
Table 3: DBRS Sample v. Other S\&P Rated Compustat Firms

This table reports simple summary statistics for Compustat firms with a DBRS ratings and an S\&P-rated with S\&P-rated Compustat firms that were not rated by DBRS. Neither sample contains financial companies $(\mathrm{SIC}=6)$.

\begin{tabular}{cccc}
\multicolumn{2}{c}{ DBRS Rated } & \multicolumn{2}{c}{ S\&P Rated } \\
\hline Mean & $\begin{array}{l}\text { Standard } \\
\text { Deviation }\end{array}$ & Mean & $\begin{array}{c}\text { Standard } \\
\text { Deviation }\end{array}$ \\
\hline 0.68 & 0.14 & 0.69 & 0.20 \\
21.5 & 40.5 & 7.3 & 18.9 \\
0.07 & 0.06 & 0.06 & 0.06 \\
$16.7 \%$ & - & $6.0 \%$ & - \\
$29.2 \%$ & - & $42.9 \%$ & - \\
$46.4 \%$ & - & $26.4 \%$ & - \\
& & &
\end{tabular}

Leverage (total liabilities / book assets)

Asset size (MM \$s)

PP\&E / assets

Share mining \& construction $(\mathrm{SIC}=1)$

Share manufacturing (SIC $=2$ or 3 )

Share regulated $(\mathrm{SIC}=4)$ 
Table 4: Cost of capital falls when DBRS becomes an NRSROs

Each row in this table represents three cross-sectional regressions. We report regressions of the change in the yield to maturity on bonds after January 2003 , the month before the SEC deemed DBRS and NRSRO in columns 1 \& 2, controlling for the difference between the DBRS rating and the average rating (from Moody's and S\&P) as of January 2003. Each regression includes an intercept which is not reported. The regressions in columns $3 \& 4$ and $5 \& 6$ report the same cross sectional models and act as a falsification test because there was no change in DBRS's regulatory status during these years. T-statistics are reported in parentheses based on residuals clustered by firm (since some firms issue more than one bond).

One-month after NRSRO (March)

Two-months after NRSRO (April)

Three-months after NRSRO (May)

Four-months after NRSRO (June)

Five-months after NRSRO (July)

Six-months after NRSRO (August)

Seven-months after NRSRO (September)

Eight-months after NRSRO (October)

Nine-months after NRSRO (November)

Ten-months after NRSRO (December)
Year in which DBRS becomes an

$$
\text { NRSRO }
$$

\begin{tabular}{|c|c|c|c|c|c|}
\hline \multirow{2}{*}{\multicolumn{2}{|c|}{$\begin{array}{cc}\text { NRSRO } \\
2003\end{array}$}} & \multicolumn{4}{|c|}{ Falsification Tests } \\
\hline & & & & & \\
\hline $\begin{array}{l}\text { DBRS-Mean rating, } \\
\text { January } 2003\end{array}$ & $N\left(R^{2}\right)$ & $\begin{array}{c}D B R S-M e a n \\
\text { rating, January } \\
2004\end{array}$ & $N\left(R^{2}\right)$ & $\begin{array}{l}\text { DBRS-Mean } \\
\text { rating, January } \\
2005\end{array}$ & $N\left(R^{2}\right)$ \\
\hline-0.04 & 89 & -0.01 & 208 & 0.01 & 497 \\
\hline$(0.96)$ & 0.03 & $(0.83)$ & 0.01 & $(0.03)$ & 0.01 \\
\hline 0.02 & 89 & -0.01 & 202 & -0.11 & 494 \\
\hline (1.11) & 0.01 & $(0.11)$ & 0.01 & (1.71) & 0.04 \\
\hline 0.03 & 90 & -0.01 & 208 & -0.08 & 499 \\
\hline (1.04) & 0.01 & $(0.33)$ & 0.01 & (1.60) & 0.02 \\
\hline 0.05 & 90 & -0.03 & 206 & -0.03 & 495 \\
\hline (1.21) & 0.03 & $(0.69)$ & 0.01 & $(0.79)$ & 0.01 \\
\hline 0.05 & 90 & -0.01 & 204 & -0.01 & 491 \\
\hline$(1.00)$ & 0.02 & $(0.03)$ & 0.01 & $(0.07)$ & 0.01 \\
\hline 0.07 & 86 & -0.05 & 201 & -0.02 & 495 \\
\hline$(1.44)$ & 0.04 & (1.41) & 0.03 & $(0.36)$ & 0.01 \\
\hline 0.09 & 86 & -0.04 & 200 & -0.01 & 495 \\
\hline$(1.44)$ & 0.07 & $(0.97)$ & 0.01 & $(0.12)$ & 0.01 \\
\hline 0.11 & 85 & -0.03 & 206 & -0.03 & 499 \\
\hline$(1.70)$ & 0.08 & $(0.85)$ & 0.01 & $(0.44)$ & 0.01 \\
\hline 0.14 & 85 & -0.05 & 206 & -0.03 & 493 \\
\hline$(2.34)$ & 0.13 & (1.18) & 0.02 & $(0.42)$ & 0.01 \\
\hline 0.16 & 89 & -0.05 & 206 & -0.03 & 499 \\
\hline (2.17) & 0.13 & $(1.00)$ & 0.02 & $(0.37)$ & 0.01 \\
\hline
\end{tabular}


Table 5: Cost of capital falls when DBRS only for firm rated better

Each row in this table represents one cross-sectional regression. We report regressions of the change in the yield to maturity on bonds after January 2003, the month before the SEC deemed DBRS and NRSRO. We control for the difference between the DBRS rating and the average rating (from Moody's and S\&P) as of January 2003. Each regression includes an intercept which is not reported. T-statistics are reported in parentheses based on residuals clustered by firm (since some firms issue more than one bond).

One-month after NRSRO

Two-months after NRSRO

Three-months after NRSRO

Four-months after NRSRO

Five-months after NRSRO

Six-months after NRSRO

Seven-months after NRSRO

Eight-months after NRSRO

Nine-months after NRSRO

DBRS-Mean rating
if DBRS rates
better

DBRS-Mean

rating if DBRS $P$-value testing $N$

rates worse

that $(1)=(2)$

$\left(R_{2}\right)$

(1)

(2)

$-0.12$

0.02

$(0.71)$

0.26

89

$(1.21)$

0.03

$(0.83)$

0.86

0.06

0.01
$(0.22)$

$-0.03$

0.10

$(0.81)$

0.17

89
0.01

$(1.43)$

$-0.04$

(1.41)

0.04

90

0.17

0.19

(2.25)

$-0.06$

(1.65)

0.03

90

0.21

(2.80)

$-0.05$

(1.50)

0.01

$-0.06$

0.27

(3.16)

(2.18)

0.00

$-0.03$

0.28

(2.73)

(0.93)

0.01

0.01

0.30

(2.89)

(0.32)

0.02

$-0.03$

(0.76)

0.39
$(3.72)$

(0.76)

$\begin{array}{cc}0.00 & 89 \\ & 0.24\end{array}$


Table 6: Cost of Capital Falls Most for Near Investment-grade Firms

Each row in this table represents one cross-sectional regression. We report regressions of the change in the yield to maturity on bonds after January 2003 , the month before the SEC deemed DBRS and NRSRO. We control for the difference between the DBRS rating and the average rating (from Moody's and S\&P) as of January 2003.

Each regression includes an intercept which is not reported. T-statistics are reported in parentheses based on residuals clustered by firm (since some firms issue more than one bond).

One-month after NRSRO

\begin{tabular}{ccccc}
$\begin{array}{c}\text { Near Investment } \\
\text { Grade }\end{array}$ & $\begin{array}{c}\text { DBRS-Mean } \\
\text { rating if DBRS } \\
\text { rates better }\end{array}$ & $\begin{array}{c}\text { NBRS-Mean Investment } \\
\text { rating if DBRS } \\
\text { rates worse }\end{array}$ & $\begin{array}{c}\text { Grade * DBRS- } \\
\text { Mean rating if } \\
\text { DBRS rates better }\end{array}$ & $\begin{array}{c}N \\
\left(R_{2}\right)\end{array}$ \\
\hline-0.35 & 0.02 & -0.04 & -0.30 & 89 \\
$(4.32)$ & $(0.33)$ & $(1.43)$ & $(2.16)$ & 0.21 \\
-0.35 & & & & 89 \\
$(3.49)$ & $(1.17)$ & $(1.06)$ & -0.17 & 0.22
\end{tabular}

Three-months after NRSRO

$-0.27$

0.11

$-0.06$

(0.51)

90

Four-months after NRSRO

$-0.20$

$(1.31)$

(2.06)

0.09

(1.75)

0.09
$(1.07)$

$-0.07$

(2.21)

(0.69)

0.15

Five-months after NRSRO

0.14

0.08

(0.85)

(1.05)

$-0.03$

0.20

(1.00)

(1.34)

$-0.01$

0.25

0.14
$(1.14)$

0.07

(0.97)

(0.42)

(1.85)

$-0.06$

Seven-months after NRSRO

0.02

0.10

(0.14)

(1.42)

(1.89)

0.28

(2.20)

0.30

$-0.07$

0.08

Eight-months after NRSRO

(0.41)

(1.04)

$-0.03$

$-0.07$

(0.49)

0.11

Nine-months after NRSRO

$-0.01$

(1.57)

0.01

(0.49)

(2.04)

0.30

(2.18)

Ten-months after NRSRO

(0.01)

0.16

(2.28)

$-0.01$

0.37

(2.65) 
Table 7: Robustness Tests

Each column in this table represents one cross-sectional regression, where the dependent variable measures the change in the yield from January 2003 to December 2003. We control for the difference between the DBRS rating and the average rating (from Moody's and S\&P) as of January 2002 . Each regression includes an intercept which is not reported. T-statistics are reported in parentheses based on residuals clustered by firm (since some firms issue more than one bond).

Near Investment Grade Indicator

DBRS-Mean rating if DBRS rates better

DBRS-Mean rating if DBRS rates worse

Near Investment Grade * DBRS-Mean rating if DBRS rates better

Mean level of rating as of January 2003

Change in rating, January to December 2003

Log of Issue Size

Indicator for Canadian issuers

$\mathrm{N}$

R2

\begin{tabular}{|c|c|c|c|c|}
\hline $\begin{array}{l}\text { Baseline model: } \\
\text { Table } 6 \text {, final row }\end{array}$ & $\begin{array}{c}\text { Include Fitch } \\
\text { when available } \\
\end{array}$ & $\begin{array}{c}\text { Add Control } \\
\text { Variables }\end{array}$ & \multicolumn{2}{|c|}{ Log of Yield Change } \\
\hline-0.01 & 0.02 & 0.02 & 0.002 & -0.006 \\
\hline$(0.01)$ & $(0.08)$ & $(0.09)$ & $(0.06)$ & $(0.20)$ \\
\hline 0.16 & 0.16 & 0.10 & 0.024 & 0.015 \\
\hline$(2.28)$ & $(2.32)$ & $(0.97)$ & $(1.97)$ & $(0.83)$ \\
\hline-0.01 & -0.01 & 0.08 & -0.007 & 0.000 \\
\hline$(0.31)$ & $(0.39)$ & $(0.81)$ & $(1.29)$ & $(0.01)$ \\
\hline 0.37 & 0.43 & 0.42 & 0.055 & 0.061 \\
\hline$(2.65)$ & (2.59) & $(2.52)$ & $(2.36)$ & $(2.27)$ \\
\hline- & - & -0.04 & - & -0.005 \\
\hline- & - & $(2.27)$ & - & $(1.69)$ \\
\hline- & - & -0.11 & - & -0.007 \\
\hline- & - & $(0.74)$ & - & $(0.29)$ \\
\hline- & - & 0.01 & - & 0.000 \\
\hline- & - & $(0.37)$ & - & $(0.04)$ \\
\hline- & - & -0.61 & - & -0.108 \\
\hline- & - & (3.23) & - & (3.39) \\
\hline 89 & 89 & 86 & 89 & 86 \\
\hline 0.32 & 0.32 & 0.50 & 0.26 & 0.43 \\
\hline
\end{tabular}


Table 8: Regression of DBRS ratting relative to rating by other NRSROs, including lagged bond Yield

Table reports regressions of the DBRS rating on the average rating by Moody's and S\&P and issue characteristics. Each rating is converted into a number (e.g. $A A A=1, A A=2$, etc), so an increase in the dependent variable means DBRS rates the firm worse. All of the regressors are measured as of the preceding month. We report each model with OLS and also using an ordered logit. Also, we report the model for all of our data and for the subset of bond rated by DBRS both before and after the change in their status. T-statistics are reported in parentheses based on residuals clustered by firm (since some firms issue more than one bond).

Only Bonds issued and rated by DBRS before DBRS

Mean Rating (S\&P \& Moody's) - 1 means AAA, 2 means AA, ..

Log of Issue Size

Indicator for Canadian Issuers

Indicator for Bonds near Investment Grade

Bond Yield

Indicator for DBRS Post NRSRO

Mean Rating * Post NRSRO

Log of Issue Size * Post NRSRO

Indicator for Canadian Issuers * Post NRSRO

Indicator for Bonds near Investment Grade * Post NRSRO

Bond Yield * Post NRSRO

\begin{tabular}{|c|c|c|c|c|c|}
\hline \multicolumn{3}{|c|}{ became an NRSRO } & \multicolumn{3}{|c|}{ All Bonds } \\
\hline 0.52 & 2.07 & 2.20 & 0.56 & 2.31 & 2.42 \\
\hline$(2.46)$ & $(6.72)$ & $(7.22)$ & (3.58) & $(8.01)$ & (8.68) \\
\hline - & -0.93 & -0.90 & - & -0.98 & -0.94 \\
\hline - & $(3.81)$ & (4.09) & - & $(4.45)$ & $(4.76)$ \\
\hline- & -1.37 & -1.23 & - & -1.33 & -1.15 \\
\hline- & $(1.78)$ & $(1.76)$ & - & $(1.83)$ & (1.76) \\
\hline- & 0.13 & 0.17 & - & -0.67 & -0.58 \\
\hline - & $(0.22)$ & $(0.27)$ & - & $(1.07)$ & $(0.92)$ \\
\hline - & - & $(0.66)$ & - & - & -0.75 \\
\hline- & - & (2.62) & - & - & (3.12) \\
\hline-0.49 & -1.48 & -4.60 & -0.50 & -4.65 & -8.29 \\
\hline (2.52) & (1.54) & (3.51) & $(2.50)$ & $(2.71)$ & (4.34) \\
\hline 0.07 & 0.06 & -0.03 & 0.07 & 0.01 & -0.08 \\
\hline (2.82) & $(0.41)$ & $(0.18)$ & $(2.74)$ & $(0.03)$ & $(0.52)$ \\
\hline - & 0.20 & 0.18 & - & 0.71 & 0.68 \\
\hline- & (1.53) & (1.54) & - & $(2.33)$ & (2.18) \\
\hline - & -0.23 & -0.40 & - & 0.75 & 0.57 \\
\hline - & $(0.32)$ & $(0.58)$ & - & $(0.99)$ & $(0.83)$ \\
\hline- & -0.02 & -0.11 & - & 0.32 & 0.21 \\
\hline- & $(0.04)$ & $(0.15)$ & - & $(0.52)$ & $(0.36)$ \\
\hline - & - & 0.60 & - & - & 0.69 \\
\hline- & - & $(2.46)$ & - & - & (2.60) \\
\hline- & 0.00 & 0.00 & - & 0.36 & 0.36 \\
\hline - & - & 0.73 & - & - & 0.62 \\
\hline Fixed Effects OLS & \multicolumn{2}{|c|}{ Ordered Logit } & Fixed Effects OLS & \multicolumn{2}{|c|}{ Ordered Logit } \\
\hline & 4,270 & & & 14,058 & \\
\hline 0.38 & 0.48 & 0.48 & 0.41 & 0.55 & 0.55 \\
\hline
\end{tabular}

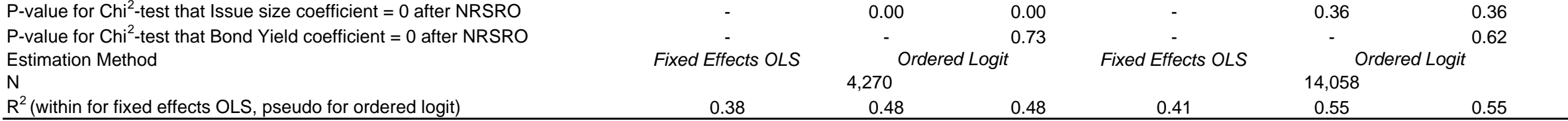

